\title{
Do Re Mi: Psikologi, Musik, dan Budaya
}

\section{Do Re Mi: Psychology, Music, and Culture}

\author{
Rinanda Rizky Amalia Shaleha \\ Fakultas Psikologi, Universitas Gadjah Mada
}

\begin{abstract}
Music has been a part of everyday human life since ancient times. Music can influence how humans feel, think, and behave. Scientific evidence also shows that there is a neurobiological basis of music. The universality of music makes everyone able to sense the emotional content in music. However, music is a product of culture so it can not be separated from cultural bias. Music is considered as a determinant of social identity. Furthermore, music influences social preferences in society. Music with certain types is considered as a marker of the group so that there is a stereotype in assessing a group. The benefits of music can be obtained in various settings such as in education and health setting. Future studies, it is necessary to review music from different perspectives such as culture, psychology, and neurobiology to be more comprehensive in order to explain the influences of music in human life.
\end{abstract}

Keywords: culture; emotion; music; psychology; social identity; stereotype

Abstrak. Musik telah menjadi sebuah bagian dari kehidupan sehari-hari manusia sejak dahulu kala. Musik dapat memengaruhi bagaimana manusia merasa, berpikir, dan berperilaku. Bukti ilmiah juga menunjukkan bahwa terdapat dasar biologis dari musik. Universalitas musik membuat siapa saja dapat merasakan konten emosi dari musik. Bagaimanapun, musik adalah produk dari budaya yang tidak dapat dipisahkan dari bias budaya. Musik dipertimbangkan sebagai sebuah faktor penentu terkait dengan identitas sosial. Lebih lanjut, musik memengaruhi preferensi sosial dalam masyarakat. Musik dengan jenis tertentu dianggap sebagai sebuah ciri atau penanda dari sebuah kelompok sehingga terdapat sebuah stereotipe dalam memberikan penilaian terhadap sebuah kelompok. Manfaat-manfaat dari musik dapat diperoleh dalam pelbagai bidang seperti pendidikan dan kesehatan. Studi-studi di masa mendatang perlu untuk mengaji musik dari perspektif yang berbeda seperti dari perspektif budaya, psikologi, dan neurobiologis agar lebih komprehensif dalam menjelaskan pengaruh musik terhadap kehidupan manusia.

Kata kunci: budaya; emosi; musik; identitas sosial; psikologi; stereotipe

\section{Pengantar}

Musik telah menjadi bagian dari kehidupan sehari-hari manusia. Kita bisa

\footnotetext{
${ }^{1}$ Korespondensi mengenai artikel ini dapat melalui: rinandarizkyas@gmail.com
}

mendengarkannya ketika makan di restoran, toko buku, pusat perbelanjaan, transportasi umum, saat olahraga, dan sebagainya. Media Info Center (2005) menyebutkan bahwa orang dewasa yang berusia lebih dari 18 tahun menghabiskan waktu rata-rata 21 jam perminggunya 
untuk mendengarkan musik melalui radio. Sama seperti suara lainnya, musik merupakan gelombang yang diproses oleh indera pendengaran kita, diubah menjadi impuls elektrik, kemudian saraf auditori mentransmisi impuls tersebut menuju ke otak dan diinterpretasi. Reseptor di otak akan bertanggung jawab terhadap dimensi dari musik seperti pitch (nada), timbre (warna nada), rhythm (irama dan harmoni), dan tempo (cepat atau lambat).

Jika ditinjau dari proses perkembangannya, bayi mampu mengenali suara pada minggu ke-20 dalam kandungan (Shahidullah \& Hepper, 1993). Bayi telah mahir membaca muatan emosi melalui pembicaraan dengan ibunya yang sering disebut sebagai motherese atau pola pembicaraan yang khusus digunakan ibu kepada bayi yang mana aspek musikalnya sangat penting. Studi lintas budaya menjelaskan bahwa motherese bersifat universal (Saint-Georges et al., 2013). Kemudian, kepekaan terhadap tangga nada serta kunci nada dasar juga telah berkembang ketika awal usia sekolah dan semakin baik seiring bertambahnya pengalaman.

Pengaruh musik tidak bisa dilepaskan dari kehidupan sehari-hari manusia. Aplikasinya dapat ditemukan dalam berbagai setting salah satunya penelitianpenelitian dalam bidang pendidikan yang menunjukkan hasil bahwa musik dapat meningkatkan skor IQ seseorang. Penelitian Schellenberg (2004) menunjukkan bahwa kelompok eksperimen yang diberikan pelajaran musik dapat menunjukkan skor IQ yang lebih tinggi daripada kelompok yang diberikan perlakuan non musik ataupun kelompok kontrol. Sebelumnya, Thompson, Schellenberg, \&
Husain (2001) juga melakukan penelitian dan menemukan bukti bahwa musik gubahan Mozart dapat meningkatkan performansi spasial individu. Sumber lain, Hallam (2010) juga menjelaskan bahwa pada masa anak-anak, musik berkaitan dengan language acquisition atau pemerolehan bahasa.

Aplikasi lain dari musik juga dapat ditemukan dalam bidang kesehatan. Grahn \& Brett (2009) menjelaskan bahwa musik dapat membantu pasien Parkinson memperbaiki gerakan motoriknya. Pasien Parkinson mampu membuat gerakan yang lebih banyak pada saat mendengarkan musik. Tak hanya itu, manfaat lain dari adanya musik adalah adanya terapi musik yang mulai digunakan dalam bidang psikologi dan psikiatri. Penelitian oleh Chang, Chen, \& Huang (2008) menunjukkan bahwa terapi musik dapat menurunkan kecemasan, stress, dan depresi pada ibu hamil.

Kemudian penelitian Maratos, Gold, Wang, \& Crawford (2008) menunjukkan bahwa terapi musik efektif dalam meningkatkan kualitas hidup (Grocke, Bloch, \& Castle, 2009). Penelitian lain yang dilakukan oleh Labbé, Schmidt, Babin, \& Pharr (2007) menjelaskan bahwa mendengarkan musik klasik setelah terpapar stressor, secara signifikan menurunkan emosi negatif dan arousal fisiologis jika dibandingkan dengan mendengarkan musik heavy metal ataupun hanya duduk dalam keheningan. Artikel ini akan lebih membahas mengenai kaitan antara psikologi, musik, dan budaya dengan harapan mampu memberikan wawasan baru terkait musik dan pengaruhnya terhadap perilaku dan proses mental manusia. 


\section{Pembahasan}

Apakah Musik sebagai Ekspresi Emosi yang Universal atau Dipengaruhi Oleh Budaya?

Musik merupakan salah satu bentuk tertua dari transmisi budaya dan ditemukan dalam berbagai bentuk pada setiap budaya dari waktu ke waktu (Wallin, Merker, \& Brown, 2000). Etnomusikologis melihat interaksi antara musik dan budaya terkait dengan bahasa, agama, dan kebangsaan. Musik adalah produk dari kepercayaan (beliefs), teknologi, kebiasaan sosial (social habits), dan psikologi dari budaya tertentu (psychology of a particular culture). Sepanjang sejarah, musik telah dianggap sebagai ekspresi dari gerakan, ketegangan, karakter manusia, identitas, kecantikan, keyakinan agama, dan kondisi sosial. Namun, yang paling umum adalah pendapat bahwa musik dianggap sebagai sebuah ekspresi emosi (Gabrielsson \& Juslin, 2003). Akurasi deteksi emosi pada potongan musik sebanding dengan deteksi emosional pada wajah atau verbal (Fritz et al., 2009).

Pada beberapa penelitian, emosi dasar dianggap dapat dikenali secara universal (Izard, 2007; Sauter, Eisner, Ekman, \& Scott, 2010). Kita dapat menggoyangkan tubuh mengikuti lagu yang menghentak atau pun menyenandungkan suatu lagu daerah tanpa tahu arti syair dari lagu tersebut. Hal tersebut menunjukkan bahwa musik bersifat universal. Auh (2002) melakukan penelitian tentang alasan mahasiswa Amerika, Korea, dan Australia dalam menyenangi musik-musik tertentu. Alasan menyenangi musik tersebut dibagi atas tiga alasan yaitu alasan emosional, musikal, dan sosial. Dari penelitian tersebut diperoleh hasil bahwa dari ketiga negara tersebut tidak terdapat perbedaan yang signifikan untuk alasan menyenangi musik. Juga tidak terdapat perbedaan yang signifikan antara partisipan pria dan wanita dari ketiga negara tersebut dalam menyenangi musik. Kemudian, pada ketiga negara, alasan emosional secara signifikan lebih tinggi dari alasan musikal dan dari alasan sosial. Analisis lebih lanjut, perbedaan yang ditemukan dalam penelitian tersebut yaitu alasan mahasiswa Korea dalam menyukai musik lebih bersifat emosional daripada mahasiswa Australia. Hal ini disebabkan karena gaya pembelajaran musik di Korea yang lebih menitikberatkan pada aspek afektif dari musik dibandingkan pada konsep tentang musik itu sendiri (aspek kognitif).

Selanjutnya, Penelitian yang dilakukan oleh Demorest (2002) menunjukkan bahwa secara biologis tidak ada bias budaya dalam mendengarkan musik. Penelitian tersebut melibatkan partisipan musisi western dan partisipan yang bukan musisi untuk mendengarkan musik Barat dan musik tradisional Cina. Hasilnya, dengan menggunakan teknik pencitraan otak fMRI, ditemukan tidak terdapat perbedaan yang signifikan antara musik Barat dan musik tradisional Cina diantara keseluruhan partisipan. Oleh karena itu, beberapa literatur menyebutkan bahwa emosi yang diekspresikan melalui musik juga bersifat bersifat universal (Do, 2011). Namun, bukti penelitian dalam konteks budaya menunjukkan bahwa budaya memengaruhi proses pengenalan emosi yang ada dalam musik. Penelitian yang dilakukan oleh Laukka \& Quick (2013) menjelaskan bahwa musik terikat dengan budaya.

Kemudian, studi lintas budaya lain yang dilakukan oleh Argstatter (2016) mencoba menjelaskan bagaimana enam emosi dasar (bahagia, sedih, takut, jijik, marah, terkejut) dipersepsikan melaui stimulus dalam bentuk musik. Penya- 
jiannya melibatkan pendengar dengan latar belakang budaya yang berbeda. Hasilnya menunjukkan bahwa emosi dasar yang disampaikan melalui musik cenderung dipersepsikan oleh pendengar sesuai dengan latar belakang budayanya. Emosi dapat dikenali lebih akurat ketika diekspresikan dan dirasakan oleh anggota kelompok dari regional yang sama. Fenomena ini dikenal sebagai in-group advantage atau keuntungan dalam grup dimana isyarat emosional (misalnya, wajah atau rangsangan vokal) lebih dikenal jika stimulus musik yang diberikan dan peserta yang mendengarkannya berasal dari budaya yang sama (Elfenbein \& Ambady, 2002). Perdebatan terkait dengan universalitas musik masih berlangsung hingga saat ini. Penelitianpenelitian yang mengaitkan antara musik dan budaya mencoba melihat adakah peran budaya di dalam interpretasi emosi dari musik.

Musik sebagai Identitas Sosial dan Stereotipe Budaya

Beberapa penelitian lintas budaya kemudian mengkaji bagaimana musik pada gilirannya menjadi sebuah penanda identitas suatu kelompok. Perkembangan budaya menunjukkan bahwa kelompok etnis yang berbeda menciptakan lagu mereka sendiri untuk menampilkan ciri khas dan juga sebagai batasan mereka dengan sosial yang lebih luas, serta memperkuat hubungan dalam kelompok. Biasanya musik terkait dengan aktivitas ritual keagamaan. Misalnya, suku Aborigin (Australia Utara) memiliki lagulagu khas suku yang hanya boleh dinyayikan oleh anggota kelompoknya saja.

Kemudian dalam masyarakat Jawa, memainkan musik (gamelan) merupakan salah satu sarana untuk berkumpul dan bersosialisasi, serta hiburan. Pengaruh dari lagu-lagu leluhur tersebut memainkan peranan penting dalam pembentukan identitas sosial kelompok. Suku-suku di dunia memiliki berbagai macam cara menyanyi yang berbeda-beda seperti misalnya orang-orang yang tinggal di pegunungan Alpen bernyanyi dengan cara yodel di mana nyanyian tersebut sahut menyahut dengan orang lainnya. Cara bernyanyi dengan yodel tersebut juga berbeda dengan yang dipraktekkan suku Pygmi. Kemudian suku Inuit di Kanada mempunyai cara bernyanyi dengan menghembuskan dan menarik nafas. Selain itu, banyak budaya di Asia yang menyanyi lewat pangkal tenggorokan, sehingga menimbulkan suara seolah-olah keluar dari hidung. Cara-cara bernyanyi tersebut akan jelas berbeda dengan teknik menyanyi opera di musik klasik. Hal ini menunjukkan bahwa setiap kelompok mempunyai cara khusus dalam mengekspresikan musik dan membuatnya menjadi identitas khusus bagi kelompok tersebut.

Kemudian, pembahasan tentang identitas sosial ini erat kaitannya dengan preferensi sosial. Seseorang cenderung untuk memilih teman karena memiliki kesamaan selera musik dari budaya yang sama (Soley \& Spelke, 2016). Sebaliknya, seseorang cenderung untuk mengabaikan orang lain yang tidak memiliki kesamaan selera musik dari budaya yang sama. Familiaritas dalam musik merupakan faktor penting dalam memilih preferensi sosial dan familiaritas tersebut sangat dipengaruhi oleh unsur budaya.

Lebih lanjut, preferensi musik terkait dengan stereotipe yang kemudian memengaruhi proses pemilihan sosial. Stereotipe mengacu pada sebuah konstruk yang dibangun secara sosial (Hilton \& Von Hippel, 1996; Sherman, Stroessner, Conrey, \& Azam, 2005) dan sangat relevan 
dengan berbagai aspek musik (Reeves, Gilbert, \& Holman, 2015). Stereotipe budaya memicu emosi secara otomatis yang berasosiasi dengan musik dengan budaya-budaya khusus. Penelitian yang menyelidiki stereotipe pada pendengar musik telah banyak dilakukan. Penelitian yang dilakukan Susino \& Schubert (2018) menjelaskan bahwa respons emosional terhadap genre musik dapat diprediksi oleh stereotipe budaya. Label yang konsisten untuk penggemar genre tertentu sebagian besar diidentifikasi tanpa batasbatas kebangsaan. Hubungan tersebut dijelaskan melalui teori identitas sosial dan fokus pada proses kognitif sebuah konsep in group dalam menilai karakter dari sebuah out group (Smith, 2014). Seperti misalnya, penilaian orang kulit putih dari kelas menengah Amerika terhadap karakter dari orang Amerika yang berkulit hitam yang preferensi genre musiknya adalah hip-hop. Sikap implisit terhadap musik mengubah persepsi seseorang. Seseorang dapat dipengaruhi oleh stereotipe dari genre musik yang mereka dengarkan. Stereotipe dapat membiaskan penilaian terhadap suatu genre. Penelitian tersebut juga menunjukkan bahwa ketika seorang diberikan informasi dengan generalisasi yang masuk akal tentang suatu genre, mengindikasikan respon mereka terhadap genre tersebut. Gosling \& Rentfrow (2007) melaporkan label yang konsisten untuk penggemar genre musik tertentu. Penelitian tersebut menyimpulkan bahwa persepsi terhadap suatu budaya dapat dimediasi oleh genre musik. Kemudian, familiaritas yang rendah dengan musik genre tertentu mengarahkan seseorang untuk cenderung lebih memiliki stereotipe yang tinggi daripada seseorang dengan familiaritas tinggi.

Studi yang dilakukan oleh Zentner, M., Grandjean \& Scherer (2008) menunjukkan bahwa musik Jazz dan Klasik terkait dengan longing, amazement, spirituality, dan peacefulness. Kemudian musik techno dan musik Latin Amerika terkait dengan excited, active, energetic, agitated, dan fiery. Sedangkan musik pop atau rock terkait dengan aggressive, angry, irritated, enraged, dan revolted. Sebuah stereotipe bisa muncul melalui asosiasi yang berulang-ulang dari genre musik dan budaya yang terkait. Anderson, Carnagey, \& Eubanks (2003) melakukan lima studi eksperimen untuk mengetahui pengaruh violent song terhadap tingkat agresivitas. Hasilnya diperoleh bahwa violent song mengarahkan seseorang pada pemikiran agresif dan perasaan permusuhan bahkan tanpa adanya provokasi.

Rawlings, Ziv, Hill, \& Barrantes-Vidal (2002) melakukan penelitian untuk melihat apakah terdapat hubungan antara lima tipe kepribadian yaitu sensation seeking, openness, psychoticism, extraversion, dan neuroticism dengan pemilihan jenis nuansa lagu (riang, sedih, tenang, dan nuansa tegang) serta ingin mengetahui apakah dalam memilih jenis nuansa lagu tersebut terdapat perbedaan antara partisipan di Australia, Spanyol, dan Israel. Hasilnya, di Australia, tipe kepribadian sensation seeking atau pencari perhatian, openness atau terbuka, dan psychoticism atau psikotisme tidak menyenangi musik yang tenang (calm). Kemudian pada partisipan di Spanyol ditemukan bahwa kepribadian sensation seeking, openness, psychoticism, dan extraversion menyenangi musik yang memiliki nuansa tegang (tense). Namun pada sampel Israel, tidak ditemukan korelasi yang signifikan antara kepribadian seseorang dengan jenis musik tertentu. Hal ini dapat dijelaskan karena Australia dan Spanyol memiliki latar kebudayaan yang hampir serupa yaitu latar belakang budaya Eropa. Meskipun 
Australia adalah benua yang terletak jauh dari Eropa, namun sebagian besar penduduknya adalah pendatang dari Eropa.

Musik dan Kaitannya dengan Psikologis Manusia serta Prosesnya di dalam Otak

Musik merupakan produk pikiran, maka dari itu elemen vibrasi dalam bentuk frekuensi, amplitudo, dan durasi belum menjadi musik bagi manusia sampai semua itu ditransformasi secara neurologis dan diintepretasikan melalui otak menjadi pitch (nada-harmoni), timbre (warna suara), dinamika (keras-lembut), dan tempo (cepat-lambat) (Djohan, 2009). Musik memengaruhi dimensi afek, kognisi, dan perilaku kita. Musik dapat membuat kita merasa senang, dan sedih bahkan marah. Salimpoor, Benovoy, Larcher, Dagher, \& Zatorre (2011) dalam penelitiannya menggunakan positron emission tomography (PET) menjelaskan bahwa terjadi peningkatan dopamine ketika mendengarkan musik yang nyaman bagi partisipan dibandingkan musik yang netral. Dopamine adalah neurotransmiter yang dapat menimbulkan perasaan senang. Musik mengaktifkan sistem reward yang sama dengan yang terlibat dalam makan dan seks. Manusia memroses, mengalami, dan merespon musik secara kompleks yang membutuhkan integrasi sensorik, motorik, atensi, emosi dan proses memori (Münte, Altenmüller, \& Jäncke, 2002; Särkämö, Tervaniemi, \& Huotilainen, 2013). Jika ditinjau dari aktivitas dari hemisfer otak, maka bagian yang lebih aktif adalah hemisfer kanan. (Särkämö et al., 2013) mengintegrasikan berbagai penelitian terkait neurobiologis dari musik untuk menguraikan area-area otak yang terlibat dalam ketika seseorang bermusik. Ketika seseorang bermain alat musik, bernyanyi, dan bergerak sesuai irama musik maka area otak yang terlibat adalah sensory motor cortex, motor cortex, premotor cortex, cerebellum, dan striatum. Ketika kita mengenali musik dan recall memori terkait musik maka yang terlibat adalah area middle temporal gyrus, medial prefrontal cortex, precuneus angular gyrus, inferior frontal gyrus, dan hippocampus. Saat musik membangkitkan emosi kita maka yang terlibat yaitu orbitofrontal cortex, cingulate gyrus, nucleus accumbens, insula, amygdala, dan ventral tegmental.

Melalui pemrosesan dalam otak, musik kemudian memengaruhi bagaimana kita merasa, berpikir, dan berperilaku. Hasil penelitian menunjukkan bahwa musik dapat menurunkan kecemasan, stress, dan depresi pada ibu hamil (Chang et al., 2008). Penelitian Maratos et al (2008) menunjukkan bahwa terapi musik efektif dalam meningkatkan kualitas hidup. Penelitian lain yang dilakukan oleh Labbé et al (2007) menjelaskan bahwa mendengarkan musik klasik setelah terpapar stressor, secara signifikan menurunkan afek negatif dan arousal. Mendengarkan musik dianggap sebagai salah satu cara untuk meregulasi afek yang efektif dan mengurangi tekanan psikologis serta merubah level energi seseorang (Saarikallio \& Erkkilä, 2007).

Ketika seseorang sedih, mereka akan memilih mendengarkan musik bertempo cepat dengan kunci nada mayor dan terbukti meningkatkan mood mereka (Hunter, Schellenberg, \& Schimmack, 2010; Knobloch \& Zillmann, 2002). Tak hanya dengan mendengarkan musik bertempo cepat (yang menunjukkan kebahagiaan) saja yang mampu untuk meningkatkan mood, sebagian individu juga lebih memilih musik sedih untuk meningkatkan mood mereka. Partisipan dalam penelitian yang dilakukan oleh Chen, Zhou, \& Bryant (2011) melaporkan 
bahwa mereka menikmati keadaannya selama mendengarkan musik sedih dan kemudian hal tersebut menyebabkan individu termotivasi untuk bangkit dari kesedihannya. Dari penjelasan tersebut kita dapat melihat bahwa baik musik senang atau pun sedih dapat memengaruhi afek individu. Lebih spesifik, musik sedih pun ternyata mampu meningkatkan mood individu.

\section{Penutup}

Musik adalah sebuah bahasa yang universal sehingga dapat diterima secara universal, namun musik merupakan produk budaya yang tidak lepas dari bias budaya. Adanya bias budaya tersebut memengaruhi persepsi seseorang terhadap musik-musik tertentu. Perdebatan apakah musik bersifat universal atau dipengaruhi budaya masih berlanjut dan penelitianpenelitian terkait musik sudah mulai banyak dilakukan untuk mengembangkan teori yang kokoh dalam bidang ini. Pengaruh musik terhadap psikologis individu juga perlu dilihat mengingat bahwa musik tidak terlepas dari kehidupan sehari-hari kita. Melalui musik kita bisa merasa senang, sedih, merasa termotivasi, dan juga tenang. Hal tersebut berkaitan dengan cara kita mempersepsi musik dan bagaimana kondisi kita saat mendengarkannya. Proses ini juga tidak terlepas dari proses yang terjadi di otak sehingga penelitian terkait musik di masa mendatang akan lebih komprehensif jika dapat ditinjau dari perspektif budaya, psikologi, dan neurobiologis.

\section{Daftar Pustaka}

Anderson, C. A., Carnagey, N. L., \& Eubanks, J. (2003). Exposure to violent media: The effects of songs with violent lyrics on aggressive thoughts and feelings. Journal of Personality and Social Psychology, 84(4), 960-971.

Argstatter, H. (2016). Perception of basic emotions in music: Culture-specific or multicultural? Psychology of Music, 44(4), 674-690. doi: $\underline{10.1177 / 0305735615589214}$

Auh, M. (2002). Reasons for liking music: Differences by country and gender among Australian, Korean, and American University Students. 7th International Conference in Music Perception and Cognition. Sidney.

Chang, M., Chen, C., \& Huang, K. (2008). Effects of music therapy on psychological health of women during pregnancy. Journal of Clinical Nursing, $17,2580-2587$.

Chen, L., Zhou, S., \& Bryant, J. (2011). Temporal changes in mood repair through music consumption: Effects of mood, mood salience, and individual differences. Media Psychology, 9(3), 695-713. doi: 10.1080/152132607 $\underline{01283293}$

Demorest, S. M. (2002). An fMRI study of cross-cultural music comprehension. 7th International Conference in Music Perception and Cognition. Sidney.

Djohan. (2009). Psikologi musik. Yogyakarta: Best Publisher.

Do, W. D. M. T. (2011). Music therapy. Retrieved from http://registration.ocali.org/rms_event _sess_handout/5942_Handout.pdf

Elfenbein, H. A., \& Ambady, N. (2002). On the universality and cultural specificity of emotion recognition: A meta-analysis. Psychological Bulletin, 128(2), 203-235.

Fritz, T., Jentschke, S., Gosselin, N., Sammler, D., Peretz, I., Turner, R., ... 
Koelsch, S. (2009). Universal recognition of three basic emotions in music. Current Biology, 19(7), 573-576. doi: $10.1016 / j . c u b .2009 .02 .058$

Gabrielsson, A., \& Juslin, P. N. (2003). Emotional expression in music performance: Between the performer's intention and the listener's experience. Psychology of Music, 24(1), 68-91.

Gosling, S. D., \& Rentfrow, P. J. (2007). The content and validity of music-genre stereotypes among college students. Psychology of Music, 35(2), 306-326. doi: $\underline{10.1177 / 0305735607070382}$

Grahn, J. A., \& Brett, M. (2009). Impairment of beat-based rhythm discrimination in Parkinson's disease. Cortex, 45(1), 54-61.

Grocke, D., Bloch, S., \& Castle, D. (2009). The effect of group music therapy on quality of life for participants living with a severe and enduring mental illness. Journal of Music Therapy, 46(2), 90-104.

Hallam, S. (2010). The power of music: Its impact on the intellectual, social and personal development of children and young people. International Journal of Music Education, 28(3), 269-289. doi: $\underline{10.1177 / 0255761410370658}$

Hilton, J. L., \& Von Hippel, W. (1996). Stereotypes. Annual Review of Psychology, 47(1), 237-271.

Hunter, P., Schellenberg, E. G., \& Schimmack, U. (2010). Feelings and perceptions of happiness and sadness induced by music: Similarities, differences, and mixed emotions. Psychology of Aesthetics, Creativity, and the Arts, 4, 47-56. doi: $\underline{10.1037 / a 0016873}$

Izard, C. E. (2007). Basic emotions, natural kinds, emotion schemas, and a new paradigm. Perspectives on Psychological
Science, 2(3), 260-280.

Knobloch, S., \& Zillmann, D. (2002). Mood management via the digital jukebox. Journal of Communication, 52, 351-366. doi: doi: 10.1111/j.1460-2466.2002.tb02 $\underline{549 . x}$

Labbé, E., Schmidt, N., Babin, J., \& Pharr, M. (2007). Coping with stress: The effectiveness of different types of music. Applied Psychophysiology Biofeedback, 32(3-4), 163-168. doi: 10.1007/s10484-007-9043-9

Laukka, P., \& Quick, L. (2013). Emotional and motivational uses of music in sports and exercise: A questionnaire study among athletes. Psychology of Music, 41(2), 198-215. doi: $\underline{10.1177 / 0305735611422507}$

Maratos, A., Gold, C., Wang, X., \& Crawford, M. (2008). Music therapy for depression. The Cochrane Database of Systematic Reviews. doi: 10.1002/ 14651858.CD004517.pub2

Media Info Center. (2005). Hours spent listening to the radio per week. Retrieved from:

http://www.mediainfocenter.org/musi c/radio_audience/hours_perweek.asp

Münte, T. F., Altenmüller, E., \& Jäncke, L. (2002). The musician's brain as a model of neuroplasticity. Nature Reviews Neuroscience, 3(6), 473-478.

Rawlings, D., Ziv, N., Hill, M., \& Barrantes-Vidal, N. (2002). Personality and liking music excerpts categorized according to 'Mood Quality': A CrossCultural Study. 7 The International Conference in Music Perception and Cognition. Sidney.

Reeves, A., Gilbert, E., \& Holman, D. (2015). Class dis-identification, cultural stereotypes, and music preferences: Experimental evidence from the UK. Poetics, 50, 44-61. 
Saarikallio, S., \& Erkkilä, J. (2007). The role of music in adolescents' mood regulation. Psychology of Music, 35(1), 88-109. doi: $10.1177 / 0305735607068889$

Saint-Georges, C., Chetouani, M., Cassel, R., Apicella, F., Mahdhaoui, A., Muratori, F., \& Cohen, D. (2013). Motherese in interaction: At the crossroad of emotion and cognition? (A systematic review). PLoS ONE, 8(10), 1-17. doi: 10.1371/journal.pone. $\underline{0078103}$

Salimpoor, V. N., Benovoy, M., Larcher, K., Dagher, A., \& Zatorre, R. J. (2011). Anatomically distinct dopamine release during anticipation and experience of peak emotion to music. Nature Neuroscience, 14(2), 257-264. doi: $\underline{10.1038 / \mathrm{nn} .2726}$

Särkämö, T., Tervaniemi, M., \& Huotilainen, M. (2013). Music perception and cognition: Development, neural basis, and rehabilitative use of music. Wiley Interdisciplinary Reviews: Cognitive Science, 4(4), 441-451. doi: 10.1002/ wcs. 1237

Sauter, D. A., Eisner, F., Ekman, P., \& Scott, S. K. (2010). Cross-cultural recognition of basic emotions through nonverbal emotional vocalizations. Proceedings of the National Academy of Sciences, 107(6), 2408-2412.

Schellenberg, E. G. (2004). Music lessons enhance IQ. Psychological Science, 15(8), 511-514. doi: 10.1111/j.09567976.2004.00711.x
Shahidullah, P., \& Hepper. (1993). The developmental origins of fetal responsiveness to an acoustic stimulus. Journal of Reproductive and Infant Psychology, 11, 135-142.

Sherman, J. W., Stroessner, S. J., Conrey, F. R., \& Azam, O. A. (2005). Prejudice and stereotype maintenance processes: Attention, attribution, and individuation. Journal of Personality and Social Psychology, 89(4), 607-622.

Smith, E. R. (2014). Social identity and social emotions: Toward new conceptualizations of prejudice. San Diego, CA: Academic Press.

Soley, G., \& Spelke, E. S. (2016). Shared cultural knowledge: Effects of music on young children's social preferences. Cognition, 148, 106-116. doi: 10.1016/j.cognition.2015.09.017

Susino, M., \& Schubert, E. (2018). Cultural stereotyping of emotional responses to music genre. Psychology of Music, (2007). doi: $10.1177 / 0305735618755886$

Thompson, W. F., Schellenberg, E. G., \& Husain, G. (2001). Research report arousal, mood, and the Mozart effect. Psychological Science, 12(3), 248-251.

Wallin, N. L., Merker, B., \& Brown, S. (2000). The origins of music. Cambridge: The MIT Press.

Zentner, M., Grandjean, D., \& Scherer, K. R. (2008). Emotions evoked by the sound of music: Characterization, classification, and measurement. Emotion, 8(4), 494-521. 